\title{
Reopening and closure of a block cave
}

\author{
H Paetzold Palabora Mining Company (Ltd), South Africa \\ P Lourens Palabora Mining Company (Ltd), South Africa \\ R Brazier Palabora Mining Company (Ltd), South Africa
}

\begin{abstract}
Palabora is a deep, hard rock, block cave in South Africa that has been in operation since 2002. After the open pit reached it maximum depth at $825 \mathrm{~m}$, the mining method was changed from open pit to block caving. The first block cave lift (Lift I) was established $400 \mathrm{~m}$ below the open pit at a depth of 1,200 $\mathrm{m}$ and has been in production since 2002, with a capacity of 33,000 tonnes ore per day, hoisted through a production shaft to surface. The second block cave (Lift II) is currently being developed $450 \mathrm{~m}$ below Lift I. Over the next 3 years Lift I is expected to ramp down slowly while Lift II ramps up, to maintain 32,000 tonnes of ore per day during steady state production. During July 2018 an unfortunate conveyor fire incident took place that forced the suspension of all conveyance of material from underground to surface. Draw from the Lift I cave was suspended for approximately 10 months while the main (conveyor 5) ore conveying system was rebuilt. Lift II development continued during this period with development material trucked up to the Lift I extraction level, which was used as a stockpile area. Although Lift I is in its final stages of production there is sufficient copper remaining to justify its re-opening. There are multiple risks that needs to be taken in consideration during the process of restarting the cave. This includes but is not limited to; re-compaction, premature and/or accelerated convergence of accesses (crosscut drives), seismicity and the uncontrolled flow of material through drawpoints. Re-opening planning included assessing risks and identifying mitigation measures, which included the sequencing of draw and continuous monitoring through visual observations and convergence measurements. The objective of this paper is to give an account of the reopening process step by step, providing a record of the actual execution (implementation), including a description of the rock mass response, the challenges experienced and how these were addressed, as well as successes achieved throughout the process. These challenges also include, but are not limited to, the impact that the Lift I and Lift II cave activities have on each other.
\end{abstract}

\section{Introduction}

Palabora Mining Company (PMC) is situated in the north eastern part of South Africa on the border of the Kruger National Park, refer to Figure 1. The mine was established in the 1960s as an open pit operation. The orebody is a low-grade carbonatite copper deposit. The open pit reached its end of life in the early 2000, as small-scale ramp scavenging took place. During the late 1990's and early 2000 a block cave was constructed below the open pit to extend the life of mine. Since 2002 the block cave has been in operation, producing at an average grade of $0.6 \%$ copper. Due to its low grade, the profitability of the operation is reliant on achieving high ore tonnages (planned at 33,000 tonnes per day), as well as recovering other by-products, the most important being magnetite. The current operational area is referred to as the Lift I footprint area. Lift I was established $400 \mathrm{~m}$ below the original open pit and is nearing the end of its Life. In 2011 the Lift II expansion project was started to extend the life of mine beyond 2033. The Lift II project involves the establishment of a second block cave below the current Lift I infrastructure. The Lift II production level is located $450 \mathrm{~m}$ below the current Lift I footprint. Lift II will make use of the existing Lift I shaft infrastructure, linked by an inclined conveyor system. The Lift II project is currently in the undercutting phase, and first ore production is scheduled during 2020. The production from Lift I currently supports the establishment of Lift II and will ensure continuous production from underground. 
On the 15th of July 2018 an unfortunate fire incident took place on the Lift I level. The main conveyor (conveyor 5) from the four underground crushers to the production shaft, caught fire. Sadly, six employees also lost their lives during the incident. All operations in the cave came to a standstill. The underground fire destroyed the four crusher-conveyor feeding arrangements and $900 \mathrm{~m}$ of conveyor belt.

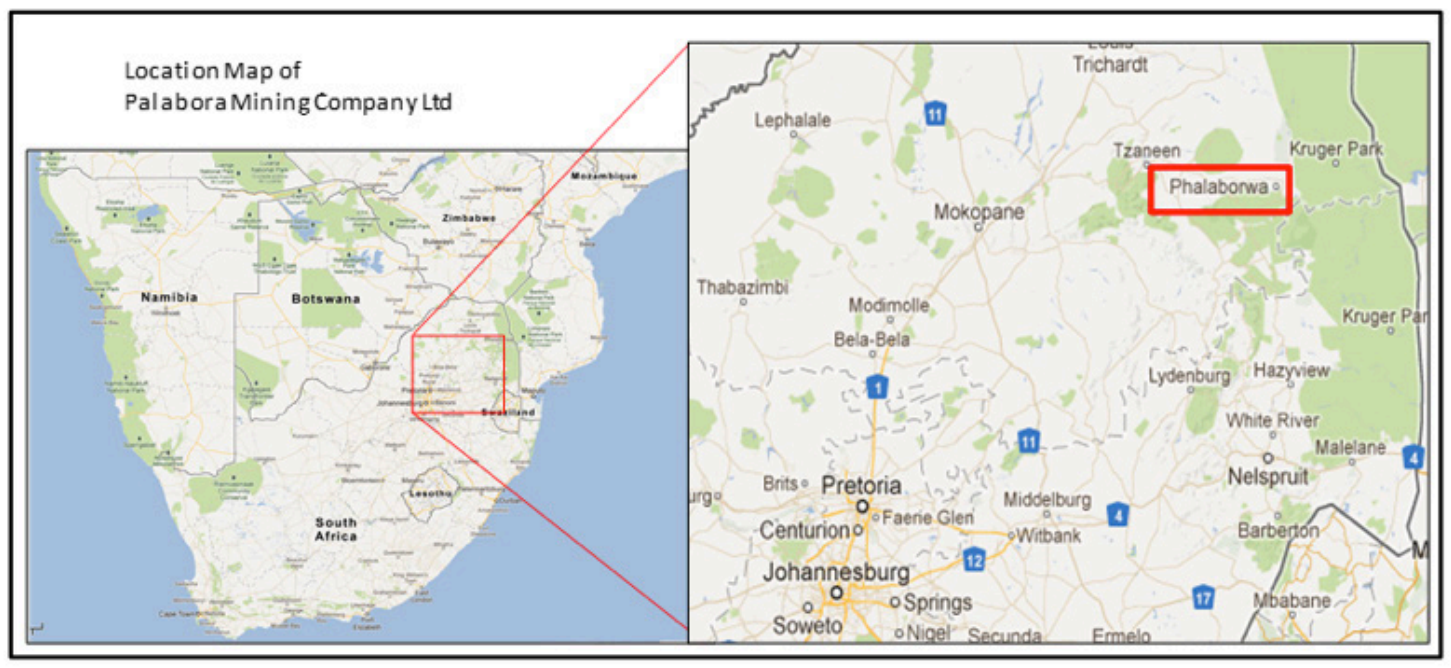

Figure 1 Location of Palabora mining company

\section{$2 \quad$ Cave loading stoppage}

On the 15th of July 2018 all production ceased on the Lift I footprint, bringing all movement within the cave to a standstill. The inactivity of the cave created a situation where several risks could develop that could significantly impact the stability of the Lift I footprint infrastructure as well as the future productivity of the Lift I cave. Figure 2 illustrates a block cave footprint with the broken caved material above and the vertical column load (stresses). During this time the following potential risks were identified:

- Compaction of caved material

- Pillar loading from the caved material

- Point-loading loading of pillars due to irregular draw during re-start

- Convergence of production tunnels

- Seismic events in the pillars

- Possible freezing of drawpoints during re-start

- Uncontrolled flow of cave material through drawpoints

All production loading operations in the Lift I cave were suspended for a period of 10 months. During this time the development on Lift II continued. The blasted development material was stockpiled in the Lift I production crosscuts. This continued for the time that it took to repair and recommission the conveying and hoisting infrastructure on Lift I.

The stockpiled material in the Lift I production crosscuts meant no manual convergence monitoring or visual observations could be undertaken. No information on the condition and potential changes to the footprint stability was available. No automated monitoring systems were installed in Lift I to facilitate remote monitoring and the only active monitoring during this period was through the existing seismic system as discussed by Glazier (Glazier 2005). 


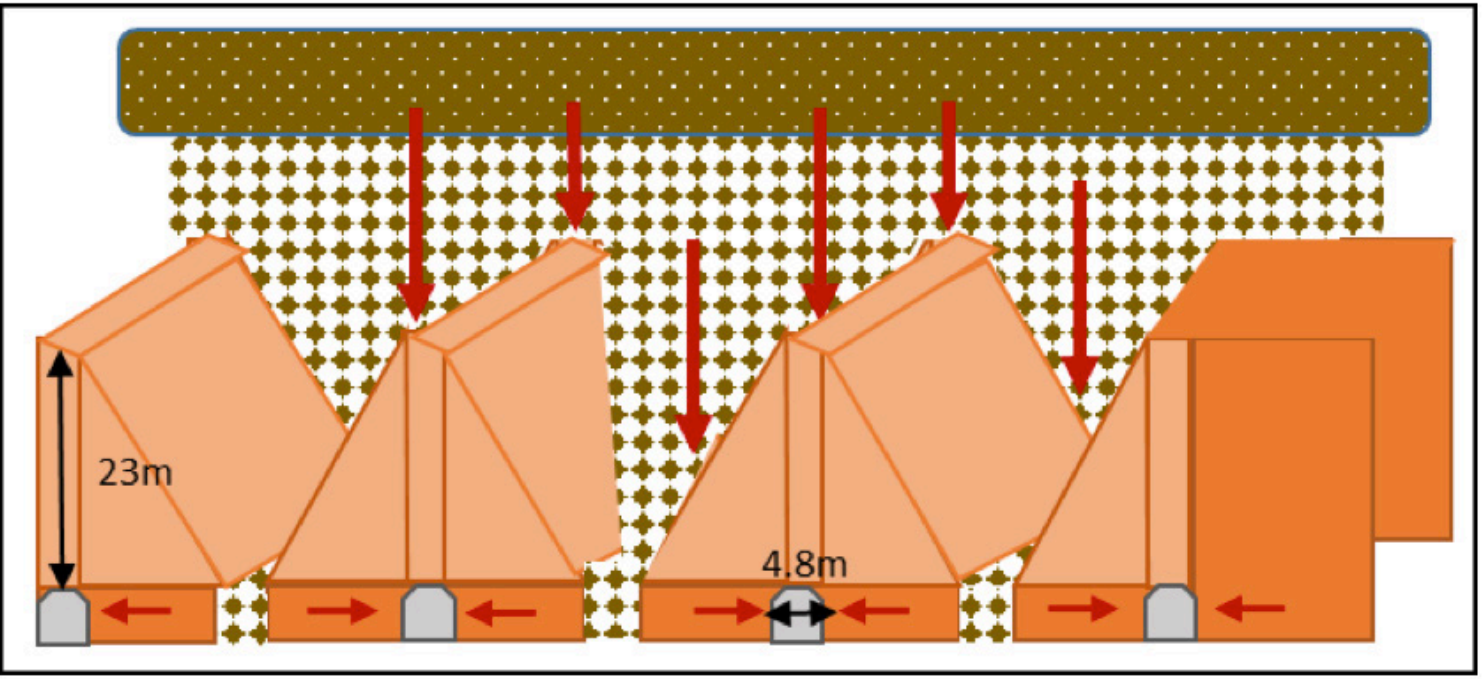

Figure 2 Block cave footprint with vertical and horizontal stresses

\section{Cave monitoring on Lift I}

During normal operations, daily convergence monitoring takes place on the production level to track any vertical and horizontal deformations of the production excavations. Along with the convergence monitoring, daily visual inspections are conducted of the production crosscuts to identify any side wall or hanging wall deformation. This informs on the stress loading conditions on the production level see Figure 3, as well as to the stability of production excavations (production crosscuts and drawpoints). The monitoring data from Lift I excavations, collected prior to and after the incident indicated the following:

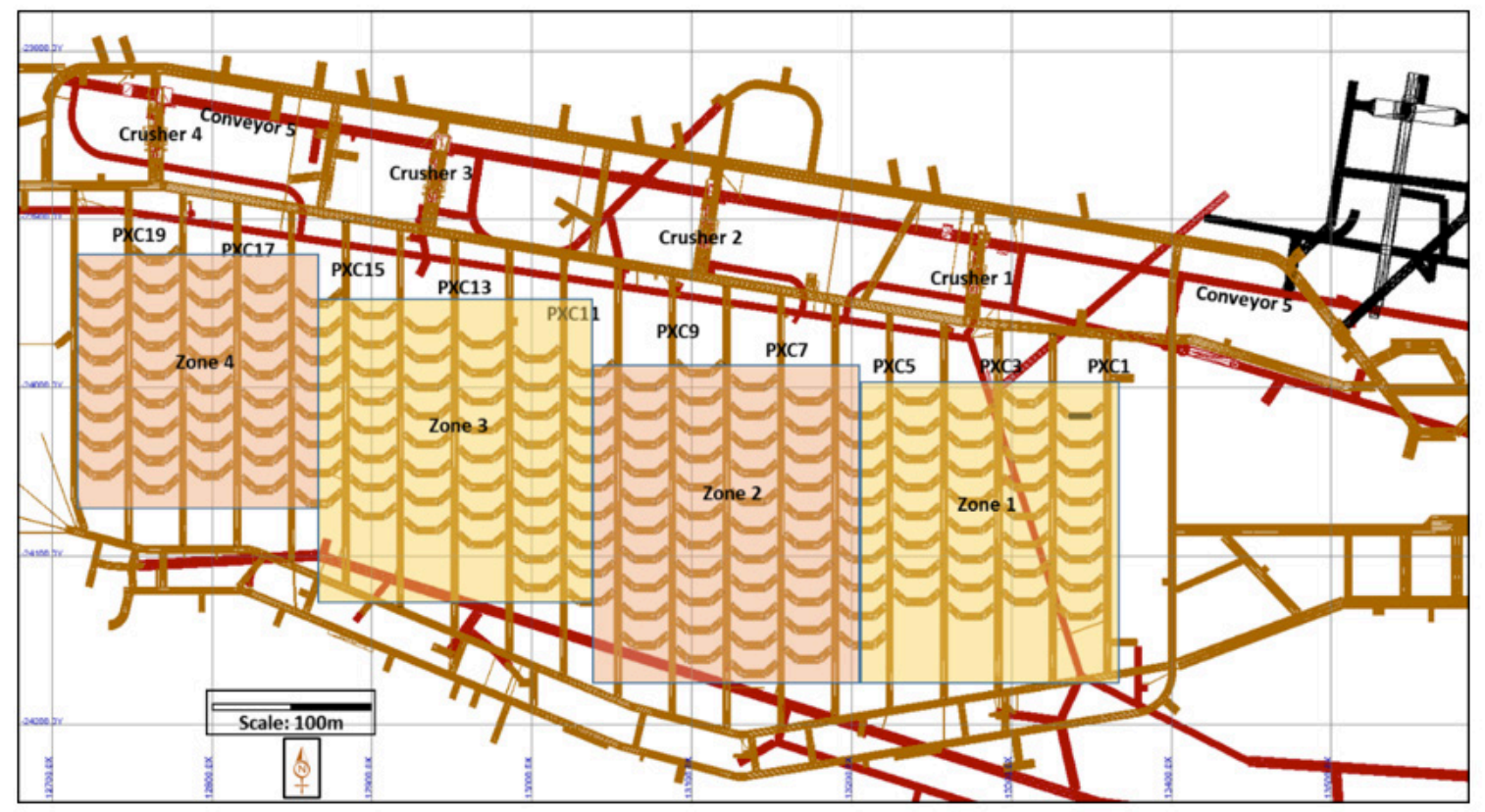

Figure 3 PMC - Lift I production level

- Uniform convergence across the Lift I footprint of less than $1 \mathrm{~mm}$, with the exception of crosscuts 9, 10, 12 and 13, where localised high convergence readings were recorded. Take note that crosscut 11 collapsed in 2004, with no access for monitoring currently (Ngidi \& Boshoff 2007). Figures 4, 5 and 6 illustrate the vertical and horizontal deformations experienced over 3, 6 and 12 months prior to the incident. The purple colour indicates high convergence areas and the green colour indicates low or no convergence. 
- Damage mapping and geotechnical inspections conducted prior to the accident indicated that the Lift I cave footprint was generally stable, with the exception of crosscuts 9, 10, 12 and 13, where localised stress induced failures were evident.

- Palabora's Lift I experience has shown that small, continuous displacements are not problematic, rather it is the sudden increases in the trends (rate of convergence) that indicates stability issues. The Purple zones in the footprint represent areas with displacements in excess of $2.0 \mathrm{~mm}$ per week. Average closure rates of $2.5 \mathrm{~mm}-6 \mathrm{~mm} /$ week were recorded within the crosscuts mentioned above. Although the convergence rates showed significant closure in these areas, no seismic related damage was reported. Figure 7 shows the convergence after the incident, once access to the footprint was obtained.

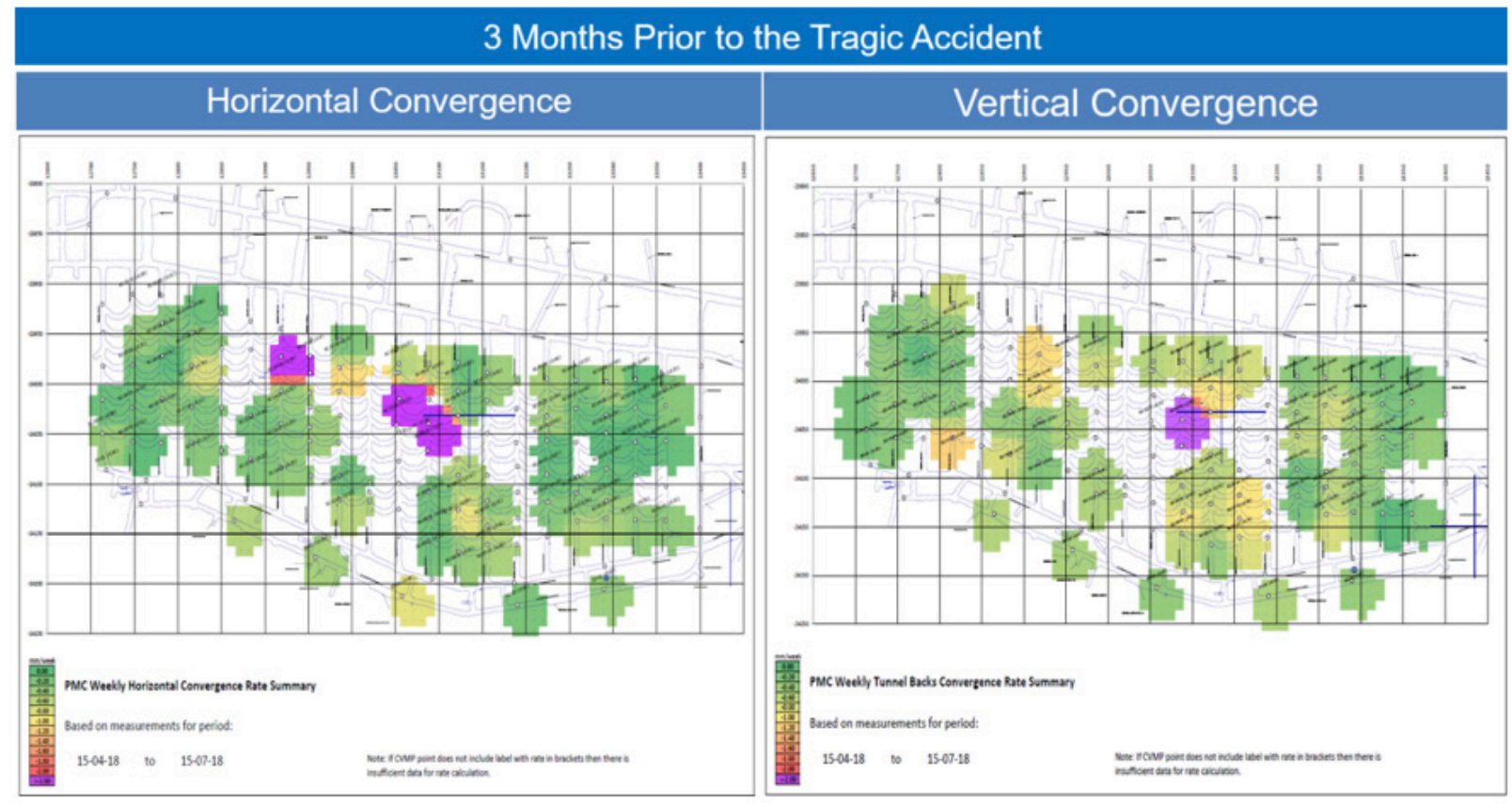

Figure 4 Convergence, 3 months prior to incident

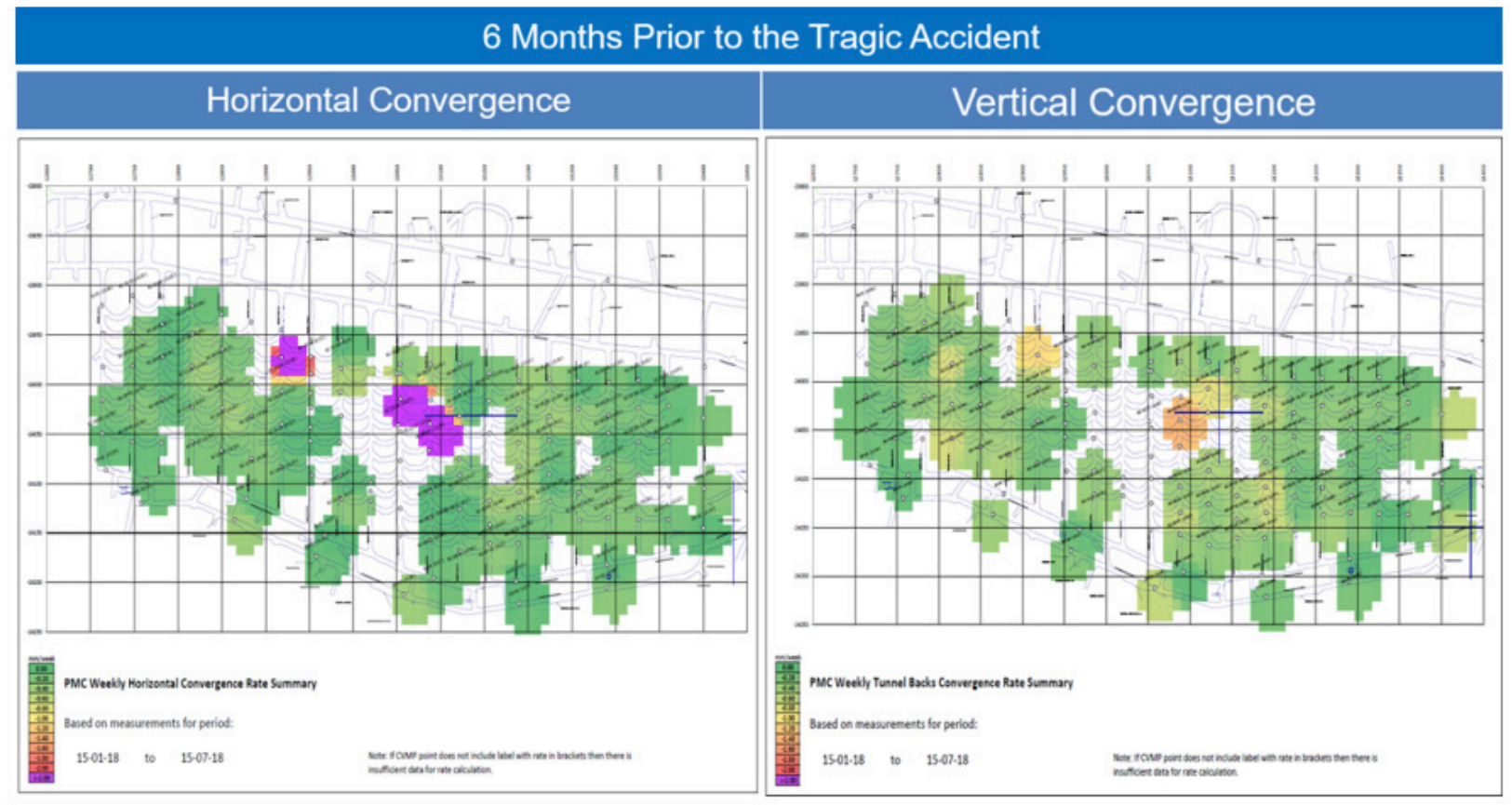

Figure 5 Convergence, 6 months prior to incident 


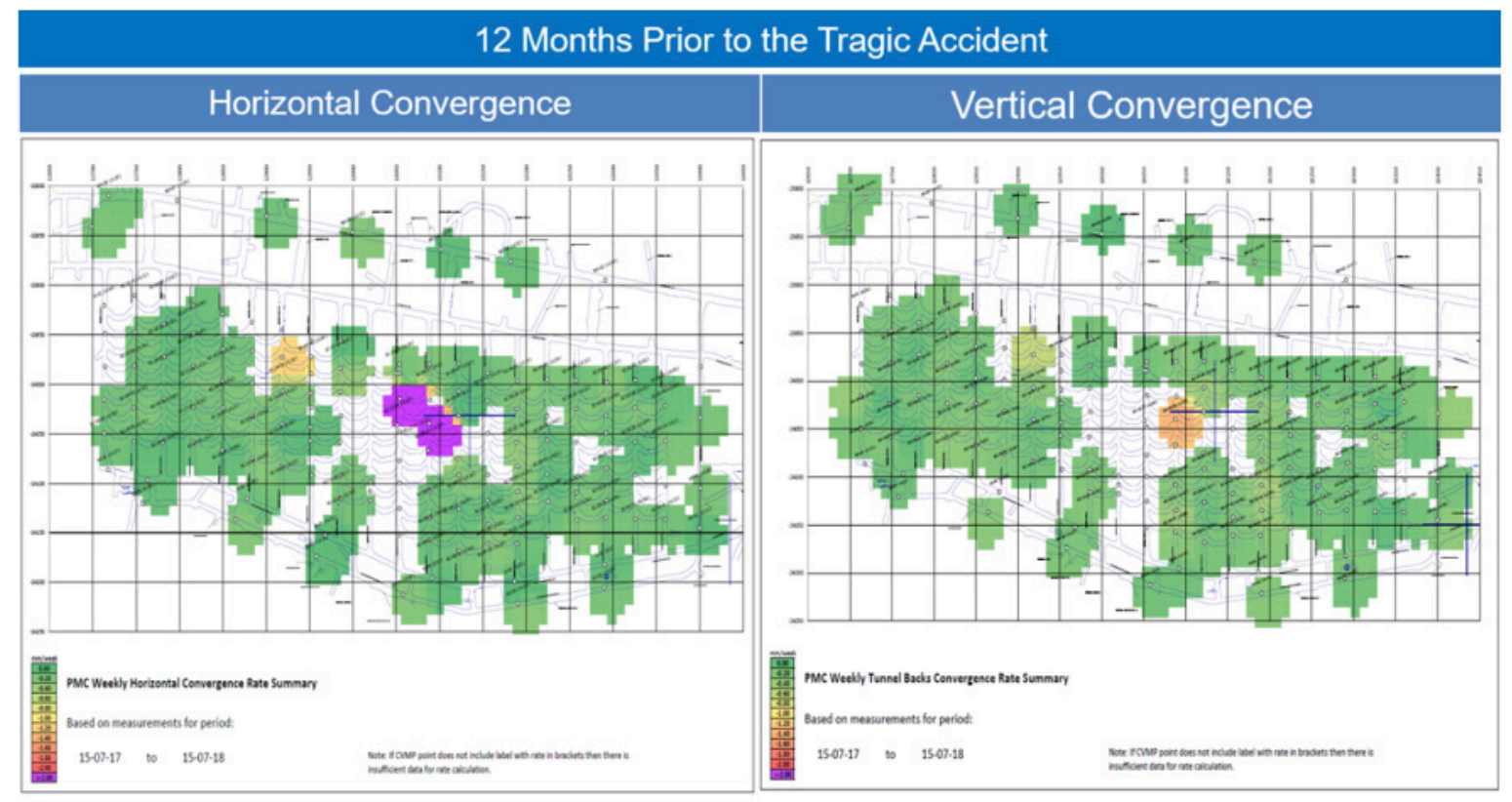

Figure 6 Convergence, 12 months prior to incident

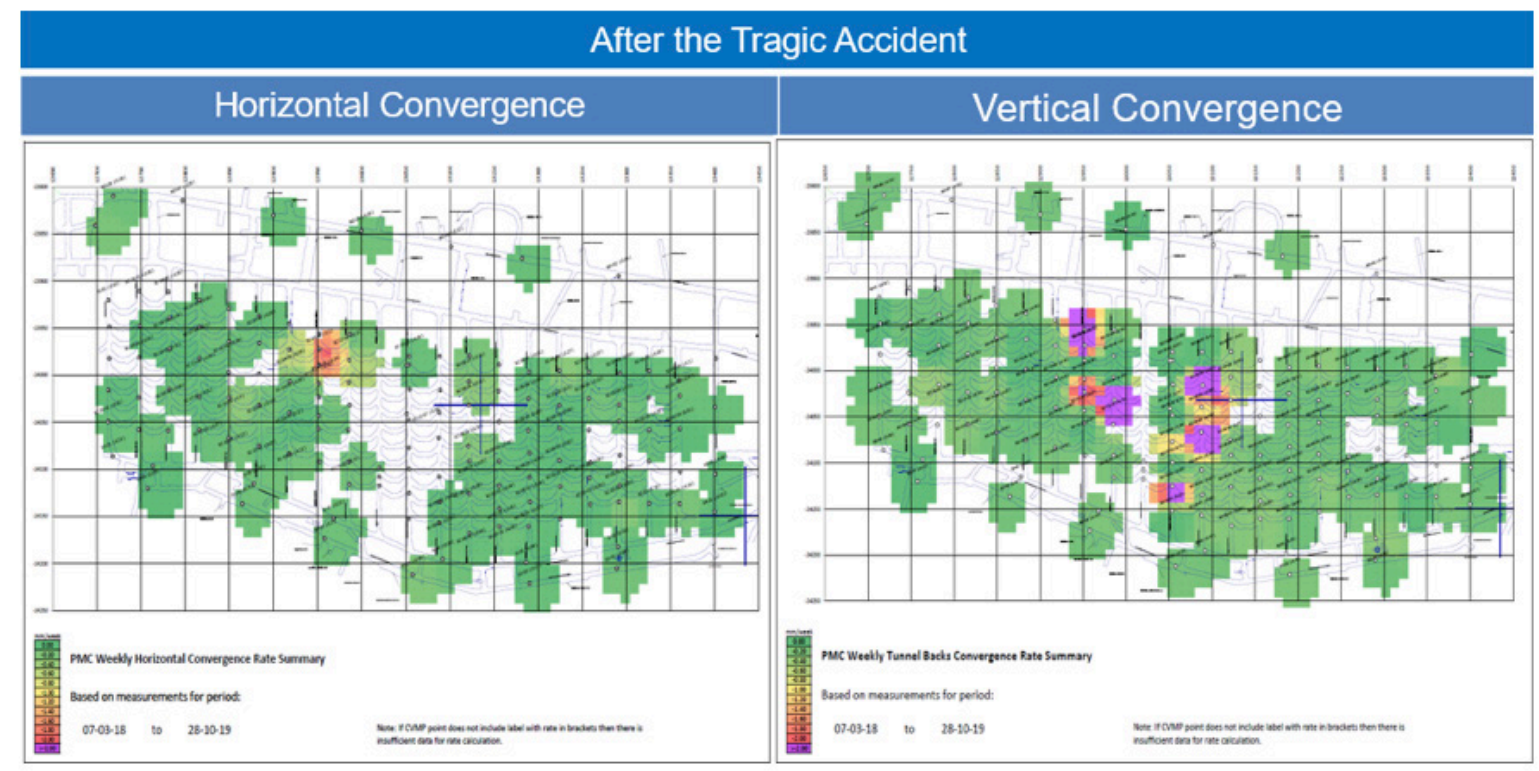

Figure 7 Convergence, after the incident

From Figures 4, 5 and 6 it can be seen that the centre of the cave experienced the greatest strain prior to the incident and constant rehabilitation work took place in these crosscuts to maintain stability and access for production from the drawpoints. The rest of the cave footprint is stable and remained stable even after the period of production inactivity, refer to Figures 4 - 7. The data for the horizontal convergence monitoring after the incident is incomplete due to the fact that some of the monitoring stations were damaged in the centre part of the footprint due to the stockpiling of Lift II material, refer to Figure 7. Damage mapping and geotechnical inspections indicated that horizontal convergence did indeed occur in the central area, in conjunction with the vertical convergence.

Due to the fact that the crosscuts were inaccessible during a period of at least 10 months, as the Lift II development material was stockpiled in the Lift I crosscuts, rehabilitation could not be undertaken in those crosscuts that were already under strain and experiencing closure prior to the incident 


\section{$4 \quad$ Lift I cave restart}

During the planning of the cave restart, the focus was to ensure that the vertical stresses from the cave column, were equally distributed and that no point loads developed through erratic, unsystematic production draw. The plan was to start drawing from the centre of the footprint, outwards towards the perimeter. The thinking was that by drawing higher in the weaker, central area, the stresses would be forced to move toward the more stable perimeter areas and then onto the sidewalls of the cave, see Figure 8. However, this was not achieved for various operational reasons, namely;

- Crosscuts were not readily available for loading in the centre of the cave when operations started up.

- Crusher 1 was the first to come online, forcing the focus to be on sector 1 and 2, due to the shorter travelling distances between the cross cuts/drawpoints and the crushers. The requirement to start production as early as possible had the effect that the crushers were phased in from east to west.

- The excessive convergence in crosscuts 9, 1012 and 13 restricted the northern access to the LHDs, access to these crosscuts were limited while the rehabilitation work was conducted. The rehabilitation of these crosscuts were undertaken as the cave re-started.

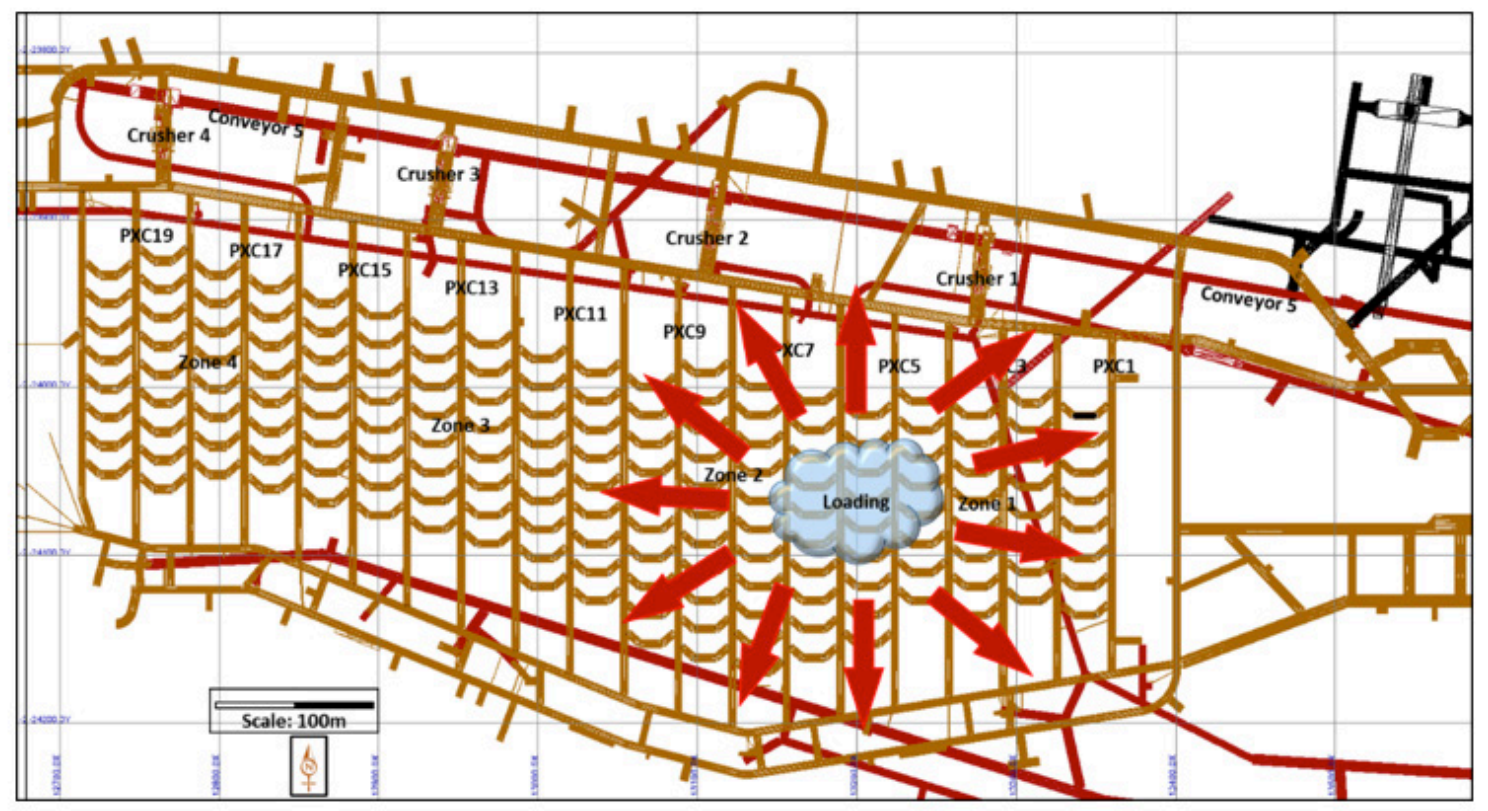

\section{Figure 8 Stress dispersed in cave}

Loading of drawpoint material from the cave commenced on the $16^{\text {th }}$ of May 2019 in Sector 1. Crusher 1 with sacrificial (conveyor) 1 feeding the crushed rock onto conveyor 5 was already recommissioned by this stage. The loading from Sector 2 commenced in late May, also utilising crusher 1, followed by Sector 3 in June and finally Sector 4 on the $6^{\text {th }}$ of July 2019. The recommissioning of crushers three and four coincided with the loading of their respective sectors, sectors 3 and 4 refer to Figure 3 for a plan view of the Lift I production area.

The loading ramp-up on the footprint took two months. During the two months the stockpiled material was loaded out in parallel with the start-up of the loading in the drawpoints from east to west.

Due to limited access, the loading in the drawpoints was started in the centre part of zone 1 and 2. This was done to be as close as possible to the centre of the cave. As the loading of the stockpiled material moved to sector 4 the loading of the drawpoints commenced in the centre (north/south) of the footprint. With a higher production call in the centre of a crosscut, reducing towards the north and the south perimeters. 
During the re-start the seismic system only recorded low intensity seismic activity in sector 1 and 2 . In Figure 9 and 10 the associated seismic events can be observed. During re-start, stress relief on the cave footprint occurred in the areas were the production loading commenced. In sector 1 the initial material movement in the cave resulted in observable stress concentrations and stress redistribution into the surrounding rock mass. The stress manifested as low intensity seismic events occurring in the rock mass surrounding the loading area, especially below the cave, refer to Figures 9 and 10. No deformation or damage was observed in sector 1 or at crusher 1 that could be related to the recorded seismic activity. As the production loading progressively moved to the west of the cave, the active production footprint area increased and stress concentrations, manifest through seismicity, were not observed in sectors 3 and 4 in the western areas, refer to Figures 9, 10, and 11. It should be noted that the higher concentration of seismic events in the east was most likely due to the higher incidence of dolerite dykes in the east and their absence in the west, thus the stiffer, more competent ( $300 \mathrm{MPa})$ dolerite dykes (Basson et al. 2016), act as stress concentrators and stress conduits, relative to the "softer" carbonatite ( 120 MPa), resulting in more seismicity. The Figures 9,10 and 11 cover the period from the $1^{\text {st }}$ of March to the $23^{\text {rd }}$ of December 2019.

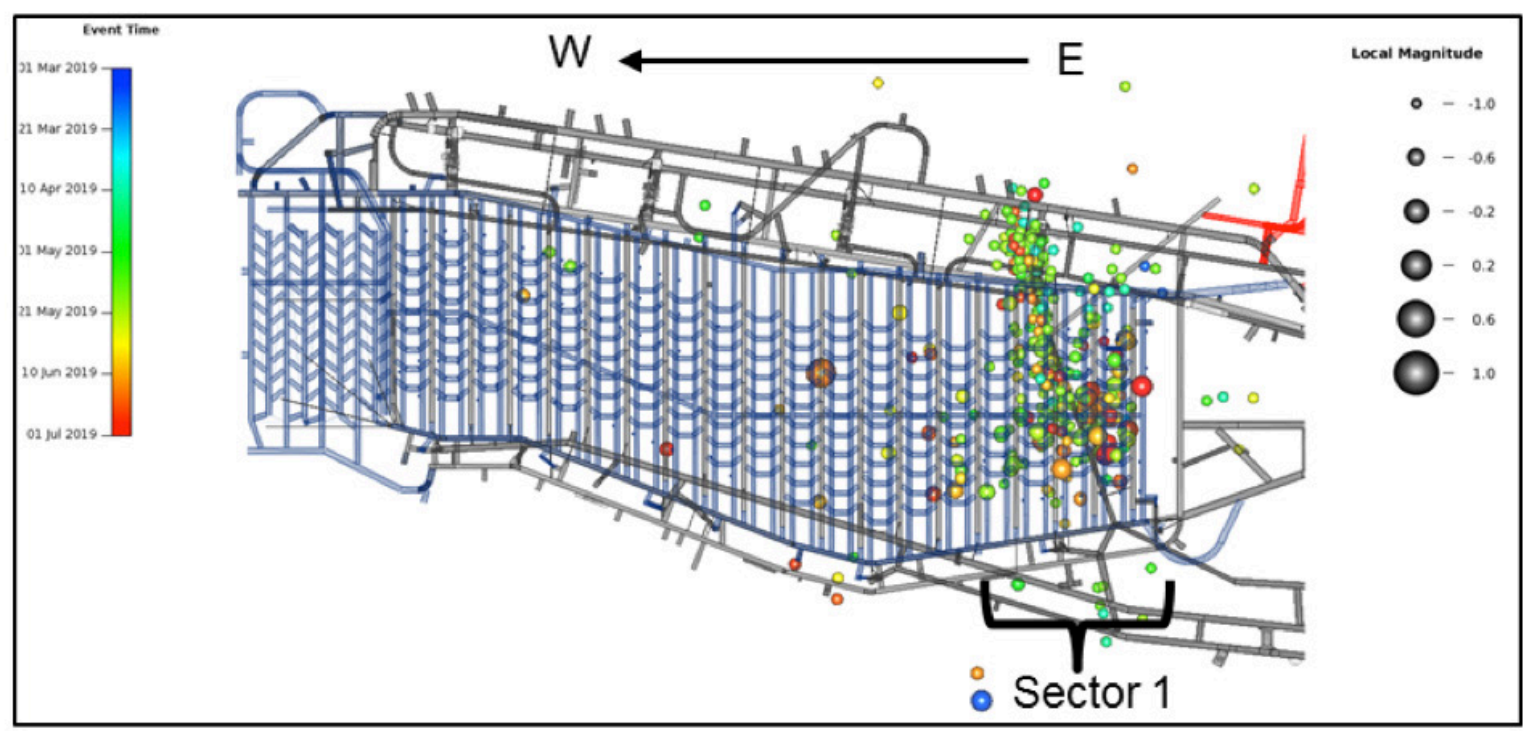

Figure 9 Lift I Seismic events during re-start, plan view (1st of March 2019 to1st of July 2019)

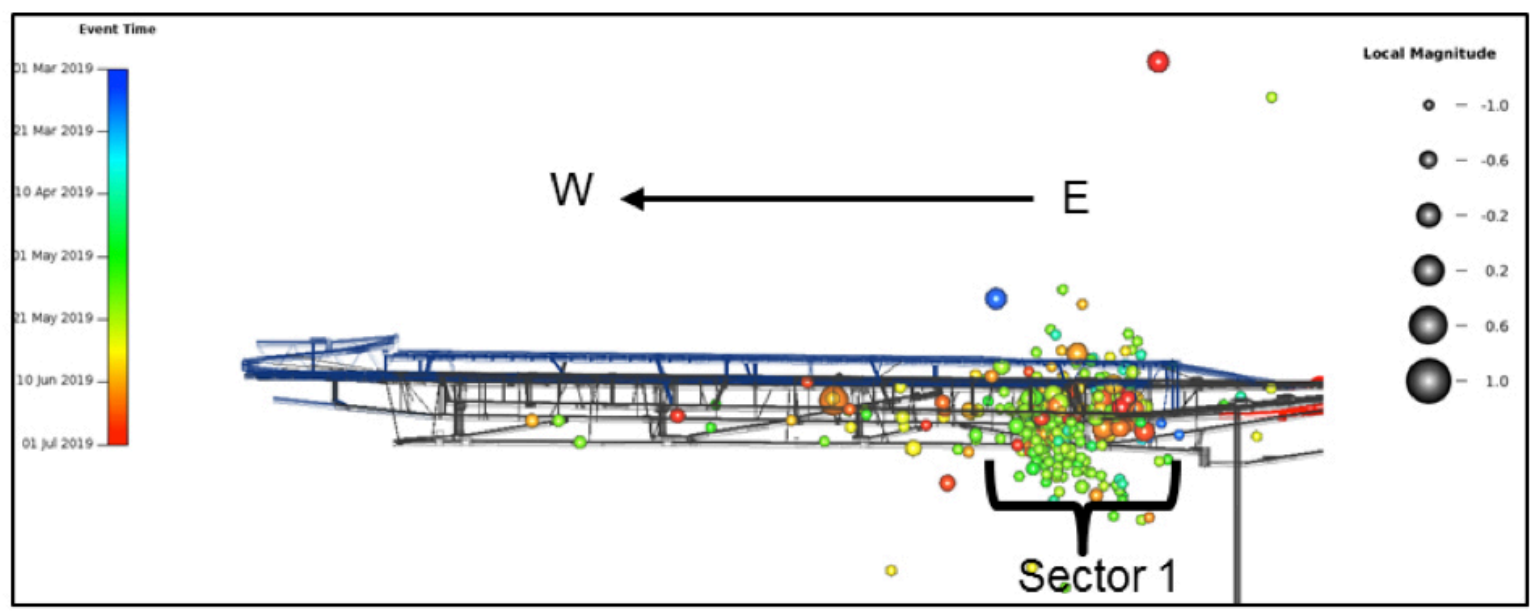

Figure 10 Lift I Seismic events during re-start section view (1st of March 2019 to 1st of July 2019) 


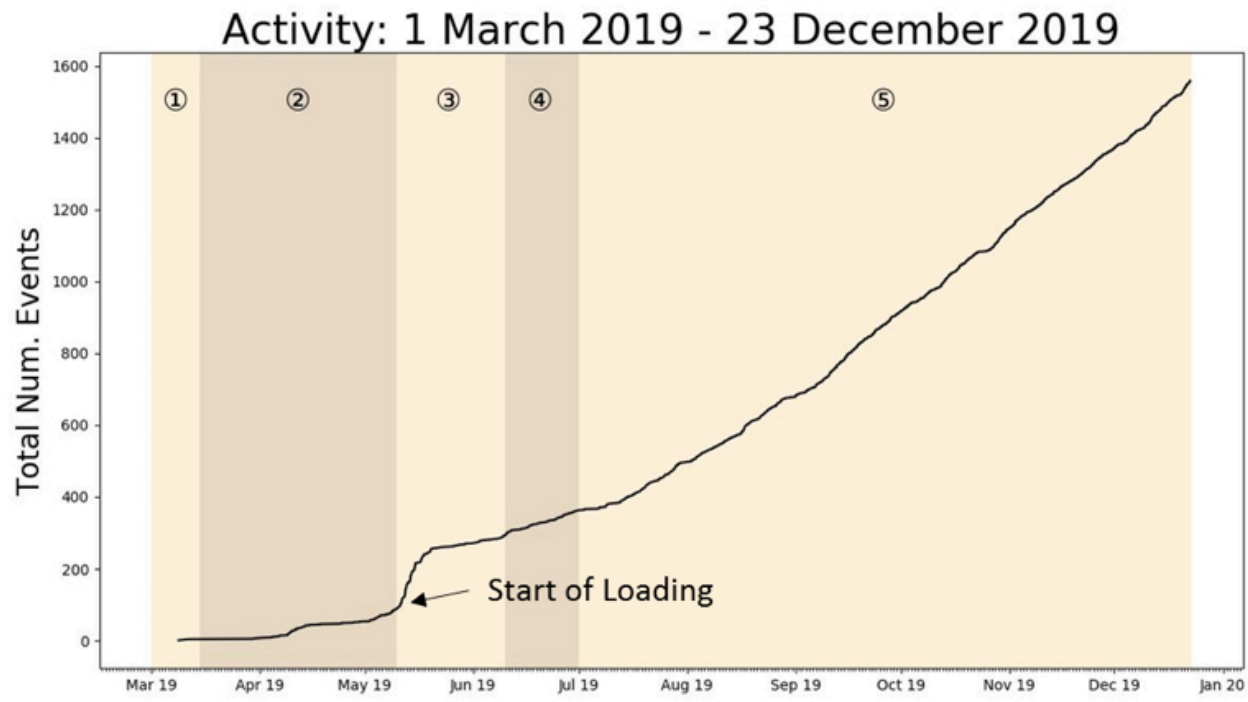

Figure 11 Cumulative seismic events over time on the Lift I level

The commencement of production loading in the east resulted in an initial stress concentration in the centre of the cave as the column load was shed from the east to the re-compacted, stagnant, material in the centre. This load shedding towards the centre of the cave footprint, was manifested by an increase in crosscut convergence and damage, observed during geotechnical inspections. It should be noted that this area was already weakened prior to the cessation of production and hence the increased material recompaction through column loading during the period of production inactivity, only served to exacerbate the existing damage, given that no 'maintenance' rehabilitation was possible in crosscuts 9, 10, 12 and 13. Experience at Palabora has shown that taking crosscuts out of production for rehabilitation allows the caved material in these areas to re-compact and hence concentrates column loading (vertical stresses); this not only causes pillar and crosscut deformation in the immediate area but also onto the adjacent crosscuts, if the area isn't brought back into production timeously. Thus during the cave re-start it was deemed critical to ensure that material within the cave was mobilised as quickly as possible through systematic and distributed production draw throughout the footprint, thereby minimising excessive stress build up on crosscuts, especially those that were known to be in a poor state.

\section{$5 \quad$ Draw point observations}

\subsection{In-rushes}

At PMC, a dry inrush is categorised as an uncontrolled, free flow of dry, fine (sub centimetre) caved material from a draw point, whilst a wet inrush is an uncontrolled, free flow of saturated, caved material from a drawpoint. Due to the dangers associated with inrushes, those drawpoints that are classified as high risk drawpoints are sealed off. The total number of wet and dry inrushes recorded as of 2007 at PMC are 322 dry and 152 wet.

A noticeable increase in the incidence of (wet and dry) inrushes were recorded during the recommencement of production. The six months prior to the incident, the rate of inrushes was recorded at an average of one event per 552,935 tonnes, whilst for 9 months after the incident the average inrush rate increased to one event per 171,536 tonnes, refer to Figure 12 for the recorded inrushes prior and post incident. The increase of the inrushes could be due to the accumulation of water in the cave during the period of no activity, as well as some concentration of fine material that took place during the start-up of the cave with the low tonnes that were drawn. The limited available data on the conditions in the cave makes it difficult to conclude that there is a direct relationship between the increased in-rushes and the period of inactivity. 

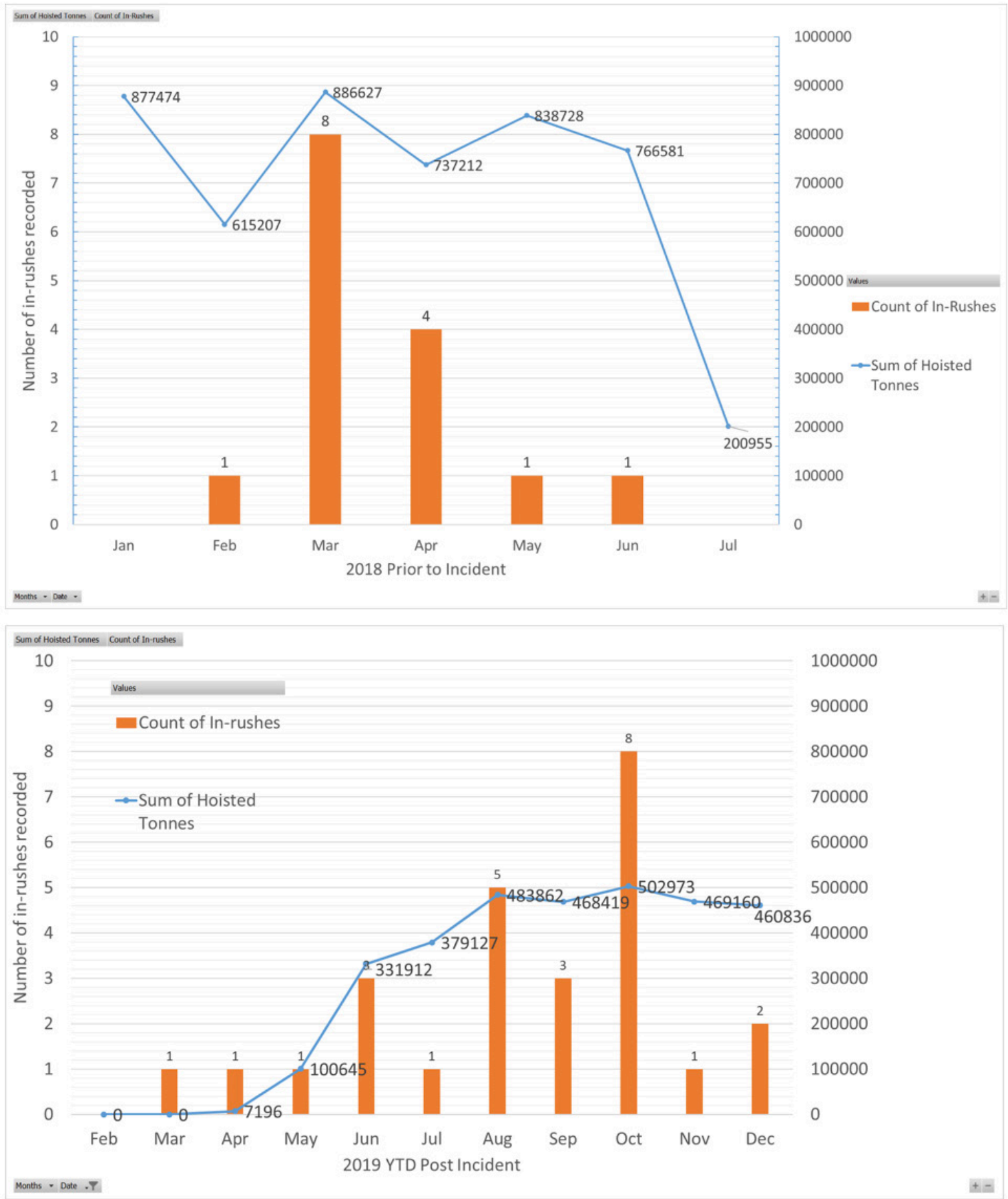

Figure 12 Count of in-rushes prior to the incident and after the start of loading relative to the tonnes

When the occurrences of in-rush events are compared to the average of the previous four years an increase of $80 \%$ was recorded. When compared to 2017 , an increase of $63 \%$ was recorded. The total number of inrush occurrences between June and November of each year since 2007 is depicted in Figure 13. The noticeable change in inrush occurrences from 2013 and 2014 relates to the introduction of PMC's policy to close all high risk drawpoints prone to inrushes. Figures 14 and 15 shows the location of all inrush occurrences since 2007 as well as those drawpoints that that have been plugged and no longer accessible for production. 


\section{In-rushes between Jun and Nov}

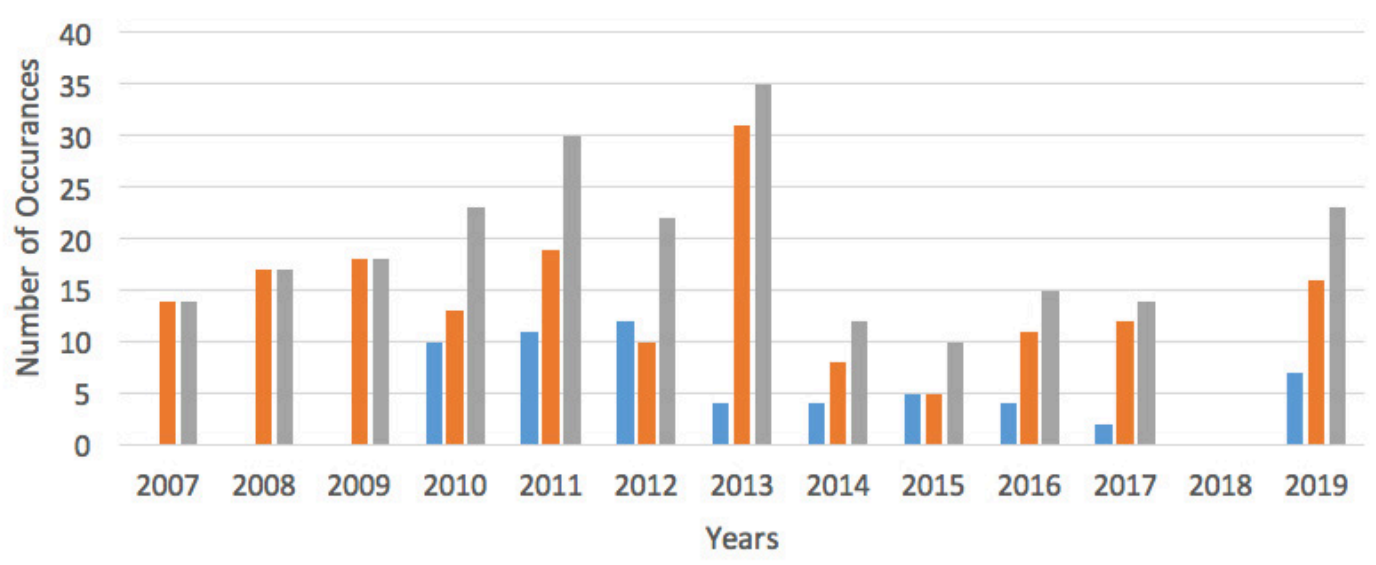

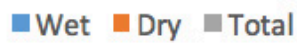

Figure 13 Count of in-rushes during June and November since 2007

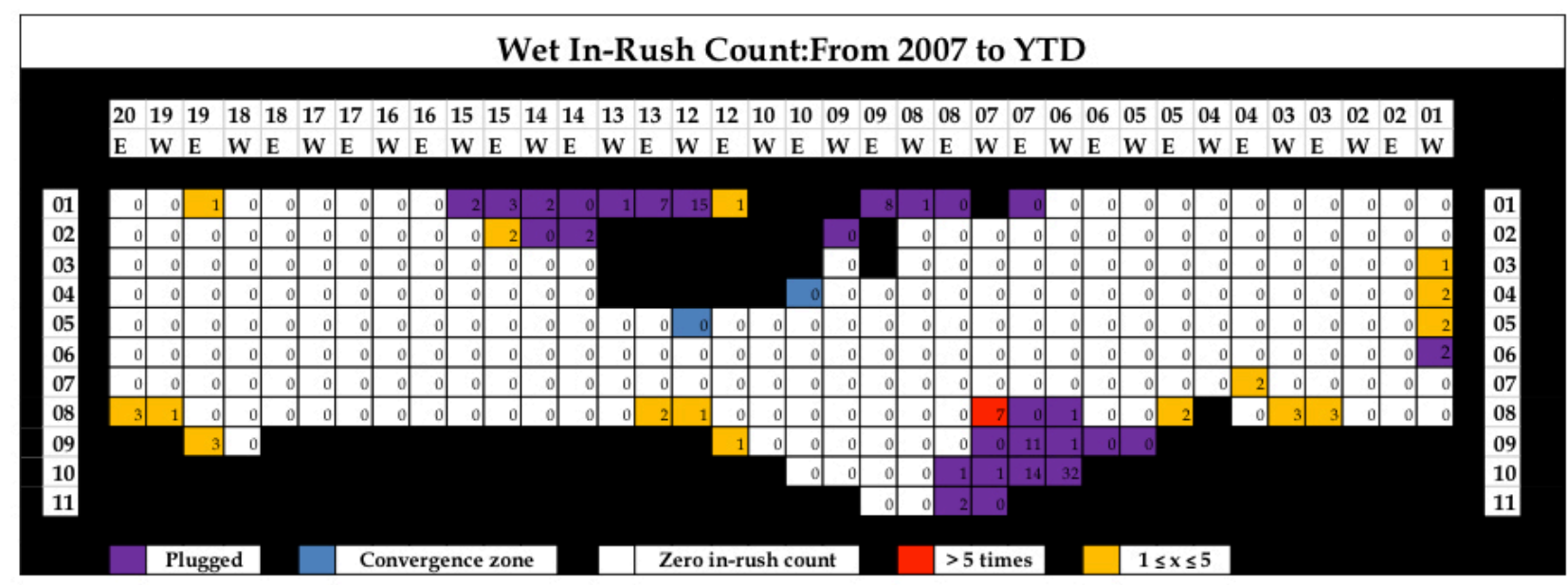

Figure 14 Count and location of wet in-rushes since 2007

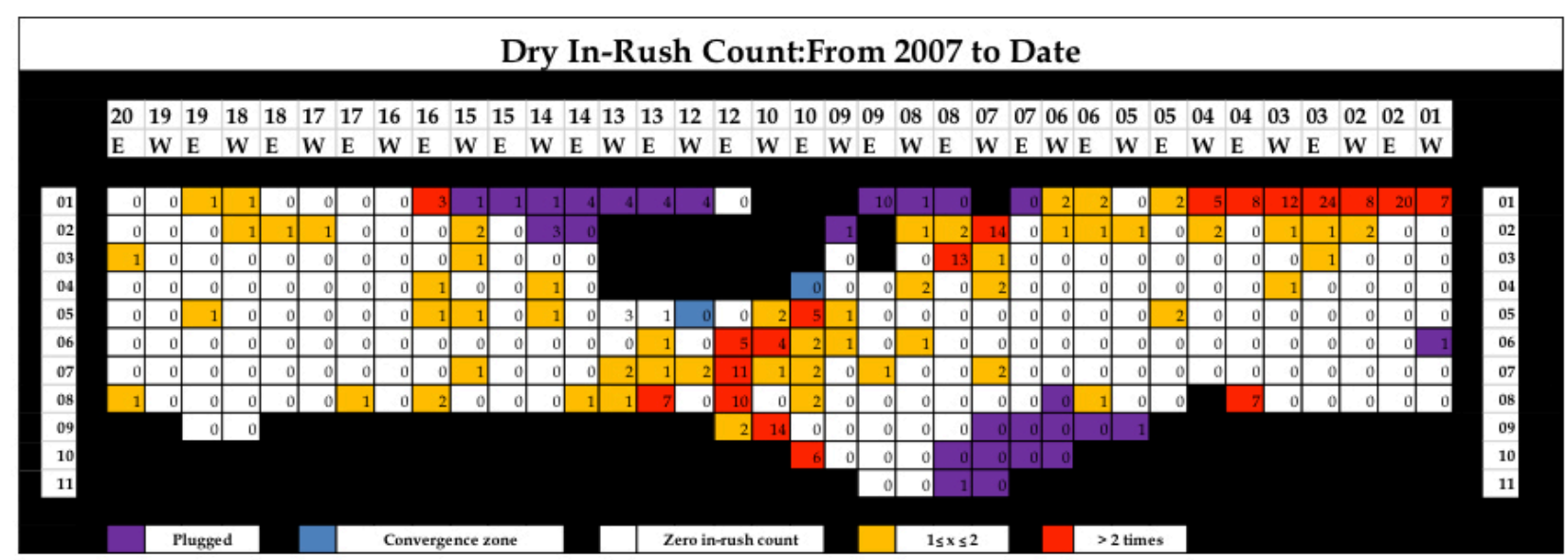

Figure 15 Count and location of dry in-rushes since 2007 


\subsection{Drawpoint hangups}

Typical hangups experienced at PMC Lift I cave occur low in the drawbell and comprise of a number of boulders that have become wedged in the throat of the drawbell or in the drawpoint itself, as depicted in the photos in Figure 16.

A comparison of the rate of hangups, expressed as tonnes drawn per hang-up, prior to and post incident suggests that an increase in the rate of hangups occurred after the event, i.e. a decrease in tonnes drawn per hang up was experienced, as illustrated in Figure 17 (the green line indicating the 3 month average tonnes per hangup for each crosscut). However, the apparent increase in recorded hangups is actually related to the operational philosophy adopted during the re-start, namely that fewer crosscuts (drawpoints) were available for production and hence the secondary breaking response was to rapidly clear all potential hangups within the available crosscuts to facilitate production. This is in contrast to the operational flexibility afforded during steady state production, when the entire footprint is available and tonnes can be drawn from drawpoints across the entire footprint. During typical steady state production, all drawpoints with hangups are left to accumulate so as not to interrupt the production cycle and thus more tonnes are drawn from a crosscut before it is released for secondary breaking to remove all hangups and oversize rocks. Thus, the increase in secondary breaking events experienced during restart was unrelated to the cave mechanics and PMC concluded that there was no significant change in the hangup or oversize rates as a result of draw inactivity and caved material re-compaction during the suspension of production post event.

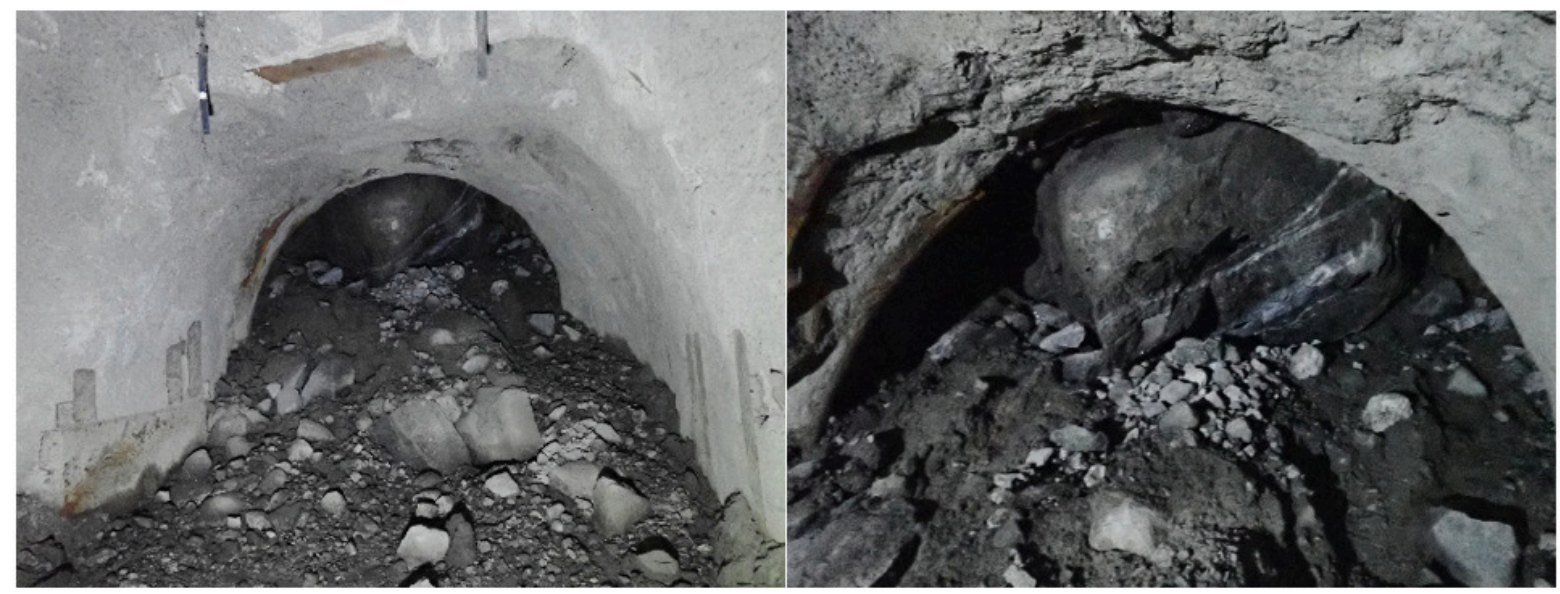

Figure 16 Tonnes mined per hangup per crosscut

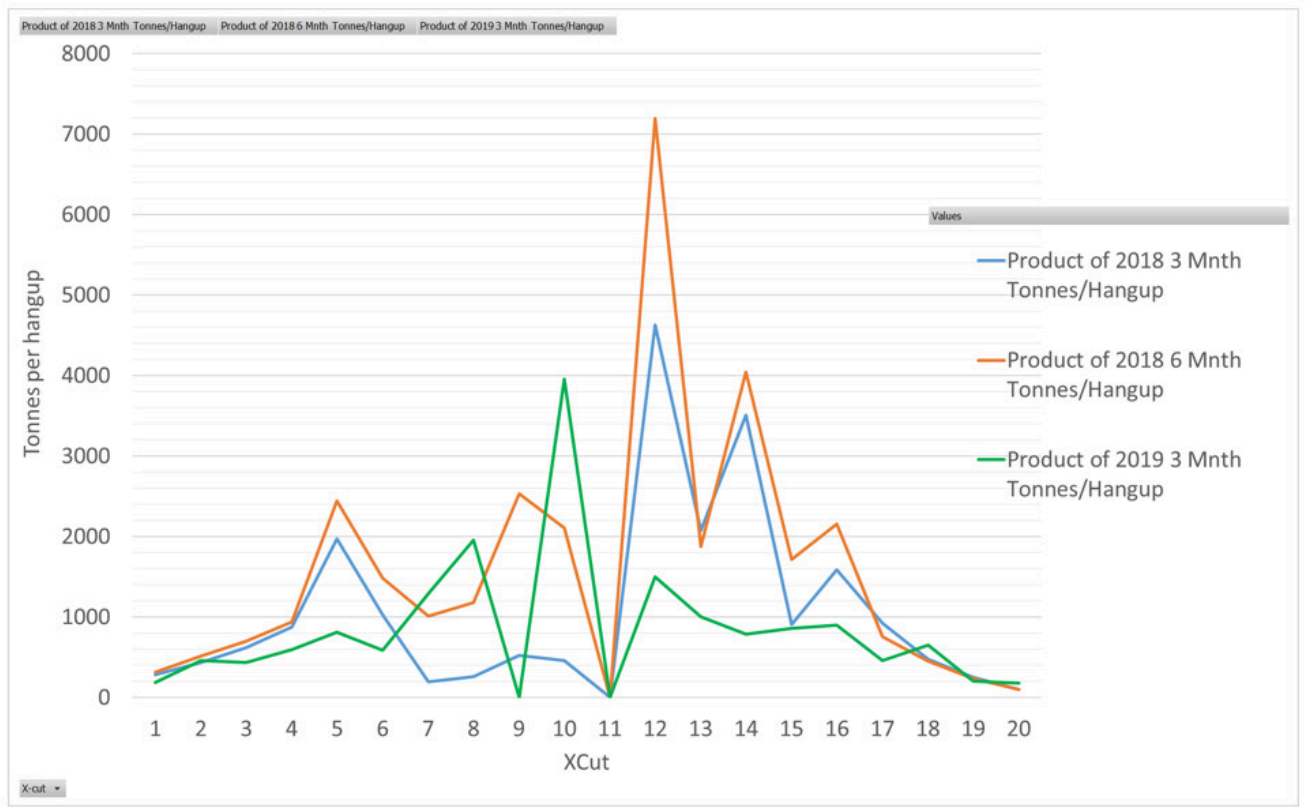

Figure 17 Typical hangups after the incident 


\section{Conclusion}

During the 10-month period of no loading within the Lift I production area convergence monitoring was not conducted due to limited access to the crosscuts. The location of the convergence did not change, the convergence was still in the same areas as before the incident. The marginal increase of convergence observed was related to the fact that no rehabilitation was done in the stressed areas. No increased stress was observed in the rest of the production level.

The re-start of the cave was planned to be from the centre outwards, however this was not possible due to operational constraints. The drawpoint loading was restarted in the east and increased seismicity was observed as stress loading took place from the loading areas to the periphery areas and below the production level. As the loading progressed to the west the rate of seismic events decreased as the loading rate increased.

The rate at which inrushes take place increased for the 9 months after the cave was re-started from one event every 552,935 tonnes loaded to one event every 171,536 tonnes.

Although it was initially thought that there was an increase in hangups, this apparent increase in recorded hangups was rather a response to the secondary breaking operating philosophy adopted during the restart.

The observations made before and after the re-start of the Lift I cave at PMC did not reveal any significant changes in stress loading or compaction that could be attributed directly to the stagnant period of production inactivity.

\section{Acknowledgement}

Andre van As and lain Ross for their valuable inputs and advice after the incident and during the re-start of the cave.

\section{References}

Basson, I, Lourens,P, Paetzold, H, Thomas, S, Brazier, R \& Molabe, P 2016, 'Structural Analysis and 3D Modelling of Major Mineralizing Structures at the Phalaborwa Copper Deposit', Journal - Ore Geology Reviews, vol. 83

Glazier, SN \& Hepworth, N 2005, 'Seismicity Induced by Cave Mining, Palabora Experience', in Y Potvin \& M Hudyma (eds), Proceedings of the Sixth International Symposium on Rockburst and Seismicity in Mines Proceedings, Australian Centre for Geomechanics, Perth, pp. 281-289, https://doi.org/10.36487/ACG_repo/574_26

Ngidi,S \& Boshoff,P 2007, 'Cave management and secondary breaking practices at Palabora Mining Company', Journal - South Africa Institute of Mining and Metallurgy, vol. 107, no. 12, pp. 782-789 